\title{
Use Cases of Grafting Machines in Taiwan Grafting Industry
}

\author{
Chin-Yuan Chang ${ }^{1,2}$, Yun-Sheng Tien ${ }^{2}$, Yu-I Huang ${ }^{1}$ \\ ${ }^{1}$ Department of Bio-industrial Mechatronics Engineering, National ChungHsing University \\ 250 Kuokuang Road,Taichung, Taiwan. \\ First. changcy@alumni.nchu.edu.tw ; Third. yuihuang@dragon.nchu.edu.tw \\ ${ }^{2}$ Machinery Laboratory of Crop Environment Section,Taichung District Agricultural Research and Extension Station \\ (TDARES), Council of Agriculture(COA), Executive Yuan \\ 370 Song Hwai Road, Tatsuen Hsiang, Changhua County, Taiwan \\ Second.ystien@tdais.gov.tw
}

\section{Extended Abstract}

The study is the use cases of the grafting machine in the tomato graft industry in Taiwan, Investigate 4 types of grafting machine: The tomato seedling grafting auxiliary equipment and conveyor type of grafting auxiliary equipment made in Taiwan, the Spanish grafting equipment and the South Korean grafting equipment. During the experiment, observe the personnel of the nursery operating the machinery to perform the grafting, and record the operation method, the operating rate of the mechanical grafting, the success rate and the survival rate of the grafted seedlings. In Taiwan, the grafting plant used by the grafting plant is tomato, the rootstock is eggplant, and a 104-hole plug tray with a diameter of 40 $\mathrm{mm}$ and a depth of $40 \mathrm{~mm}$ is used for nursery[1,2].

The grafting machinery imported from South Korea is produced by Helper Robotech Company, the model is AFGR800CS [3], use 2 people to operate the grafting machine, and the left side of the machine supplies the root anvil, and the right side of the machine supplies the scion. AFGR800CS has a graft success rate of $90.1 \%$, a survival rate of $91.5 \%$, and a graft speed of 530-660 plants/hr/2 people.

The grafting machinery imported from Spain is produced by Conic-System Company, the model is EMP-300 [4], operated by a single person, artificially supply spikes and rootstocks, and the foot switch starts the machine for grafting operation, which is a semi-automatic grafting machine. EMP-300 has a graft success rate of $88.9 \%$, a survival rate of $90.9 \%$, and a graft speed of 300-360 plants/hr/1 person, the efficiency is about 1.44-1.73 times faster than traditional manual grafting( 208 plants/hr/1 person).

The single-operated "tomato seedling grafting auxiliary machine" is developed, the results show that the average grafting time of the operator who has just contacted the grafting machine and operated the auxiliary equipment for grafting tomato seedlings is $18.5 \mathrm{sec}$, and the operating rate per hour is 194 plants, after training, the average plant grafting time of the operator is $14.1 \mathrm{sec}$, the operation rate is 256 plants per hour, and the operation rate can be accelerated by about 3-4 seconds after training. The success rate of grafting auxiliary equipment for tomato seedling grafting was $96.5 \%$, and the survival rate after healing operation was $91.3 \%$.

The conveyor type of grafting auxiliary equipment was operated by 4 people, the four operators who first contacted the machine had a total number of 810 plants grafted in 1 hour; the grafting efficiency was 202.5 plants/hr/person. After 48 hours of training, the total number of grafted plants increased to approximately 1,000 plants/hr, and the operating efficiency increased by $19 \%$. The conversion of operating efficiency is 250 plants/hr/person, which is $22.5 \%$ higher than the traditional manual grafting efficiency of 208 plants/hr/person.

In Taiwan, the mechanization and automation of the production of seedling grafting is an inevitable trend, so this study uses 4 grafting machines for testing and application, to solve the problem of the lack of grafting manpower in the peak season of the nursery.

\section{References}

[1] Chang Chin-Yuan, Tien Yun-Sheng. 2019. Development and Application of Conveyor Type Grafting Auxiliary Machinery. Proceeding of 2019 Symposium on Development and Application on Labor-saving Agricultural 
Machinery. Taiwan. P83-92. Available:

https://www.tdais.gov.tw/upload/tdais/files/web_structure/12534/\%E8\%BC\%B8\%E9\%80\%81\%E5\%B8\%B6\%E5\%A

В\%81\%Е6\%8Е\%A5\%Е8\%BC\%94\%Е5\%8A\%A9\%Е6\%A9\%9F\%Е5\%85\%B7\%Е4\%B9\%8B\%Е7\%A0\%94\%Е7\%9

9\%BC\%E6\%87\%89\%E7\%94\%A8.pdf

[2] Hsueh-Shih Lin, Chin-Yuan Chang, Chang-Sheng Chien, Shih-Fang Chen, Wei-Ling Chen, Yung-Chu Chu, Ai-Hua Yang, Yu-Kuang Hseuh, Sheng-Chih Chang. 2016. CURRENT SITUATION OF GRAFTED VEGETABLE SEEDLING INDUSTRY AND ITS MECHANIZATION DEVELOPMENT IN TAIWAN. FFTC \& Tainan-DARES International Workshop on Grafting to Improve Fruit Vegetable Production. P65-76. Available:

https://pdfs.semanticscholar.org/14cf/9b58f761c5be6a6133718bb7016a414471fe.pdf

[3] Korea Helper Robotech . (2020,July 7) Available: http://helpersys.en.ec21.com/Grafting_Robot-2012260_2012262.html

[4] Spain Conic-system . (2020,July 7) Available: https://www.conic-system.com/wp/gallery/emp300/ 